\title{
Does Internationalisation Increase Exchange Rate Exposure? -Evidence from Chinese Financial Firms
}

\begin{abstract}
This study investigates both the symmetric and asymmetric exchange rate exposures of Chinese financial firms in the context of an accelerated pace of RMB internationalisation. We find that an increasing number of Chinese financial firms are exposed to negative symmetric effects from the change in the trade weighted effective exchange rate. The evidence concerning asymmetries shows that after 2009 negative exchange rate shocks (a weaker RMB) have a stronger effect on exposures than positive shocks(a stronger RMB). Changes in the bilateral exchange rate also have a significant impact on firm returns, given the importance of the USD in the effective exchange rate. Further, the empirical analysis reveals that exchange rate exposures are associated with firm level characteristics including total assets, earnings per share, net cash flows, investment incomes, total liabilities and firm size. Finally, we suggest that domestic and foreign stakeholders need to pay close attention to the movement of the Yuan's exchange rate before it becomes completely convertible.
\end{abstract}

JEL Codes: C58, F3, G15.

Keywords: exchange rate exposure, RMB internationalisation, Chinese financial firms. 


\section{Introduction}

The "flow-oriented" exchange rate theory suggests that currency movements have a significant impact on firm values (Dornbusch and Fischer, 1980; Phylaktis and Ravazzolo, 2005), as firm returns are exposed to unanticipated changes in exchange rates (Hodder, 1982; Jorion, 1990; Dominguez and Tesar, 2001; 2006; Martin and Mauer, 2003). This is defined as exchange rate exposure, which is viewed as an important source of risk for international firms ${ }^{1}$. Unexpected exchange rate movements of this kind are a basic feature of global financial markets, especially they are floating rates, which are usually recognised as the source of currency risks. However, we also have to bear in mind that some fixed exchange rate systems can also carry a source of uncertainty if the central bank or government is not able to sustain the parity and the currency is subject to a speculative attack. Examples of this are the attacks suffered by the Mexican peso in 1992, the Thai baht in 1997 or the Argentinian peso in 2002, when they moved from a one-to-one rate against the US dollar to a floating exchange rate as a consequence of their debt crises. Previous studies have examined currency exposures in developed economies with independent floating rates ${ }^{2}$ like the US, Japan, Canada and Australia (Bodnar and Gentry, 1993; Khoo, 1994; Williamson, 2001). Less attention has been paid to currency exposures in emerging markets given that these economies are often criticised for their fixed exchange rate regimes or managed floating exchange rate regimes. An interesting case is the Yuan or Renminbi, RMB, since on some occasions trading partners have accused China of "manipulating" the RMB exchange rate.

The exchange rate policy in China has gone through dramatic changes since 1994 and the Yuan is becoming flexible and convertible. China unified the dual system of the foreign exchange market in 1994 and the daily floating range of USD/RMB (units of RMB per unit USD) was limited at $0.3 \%$. The managed floating exchange rate regime was introduced in July 2005 and the RMB exchange rate started to be quoted to a basket of currencies rather than being pegged to the USD only. The daily

\footnotetext{
${ }^{1}$ Typically, firms are exposed to transaction, translation and economic exposures. Transaction exposure is the impact of exchange rates on the cash flows of specific identifiable foreign currencydenominated transactions. Translation exposure is also called accounting exposure, but it is not considered here since it does not affect cash flows. Economic exposure encompasses the competitive and indirect effects of exchange rate risk. Unlike the other two types of exposure, this dimension can also affect domestic firms (Martin and Mauer, 2003; Bartram, 2007; Booth and Rotenberg, 2010)

${ }^{2}$ See the IMF for detailed classifications of exchange rate regimes.
} 
trading band for the currency was widened to $0.5 \%$ in 2007, and further expanded to $1 \%$ in 2012 , and to $2 \%$ in 2014 . China's state council also announced its intention to widen the band to $3 \%$ in 2015 . The historical daily trading fluctuation range for the GBP to the USD during 01/2012-05/2015 was -1.898 (min) to 1.914 ( $\max$ ) with an average of 0.00056 , while the daily fluctuation of the USD to the RMB was $-1.093(\mathrm{~min})$ to $1.102(\max )$ with an average of -0.00344 over the same period. ${ }^{3}$ This makes research into the currency exposure in China compared to the two independent floating rates in the UK and US of topical importance in the current global economic climate. This can also be explained by two other points about China. First, the Chinese government is trying to internationalise its currency, the Yuan, which may expose Chinese firms to exchange rate changes since the Yuan is becoming increasingly popular in international transactions. ${ }^{4}$ Second, the Chinese economy is closely linked to the global economy and any turmoil in the Chinese financial market could spill over into other markets.

In this paper we focus on the currency exposure of Chinese financial firms, which matters a great deal both domestically and internationally. This is partly because Chinese financial firms are actively reacting to their government's calling to internationalise the RMB by issuing offshore RMB bonds, investing overseas, offering loans, etc. The values of firms must be subject to exchange rate movements in the currency transaction and translation process. This could be of great concern for both firm managers and investors alike. The authorities also need to pay attention to the currency exposure of financial firms as crises have historically tended to emerge from financial markets. At the same time, foreign institutions and investors need to understand the currency exposure of Chinese financial firms, since a potential crisis or default happening in these firms could cause important damage or serious losses to foreign clients. Trade partners are also concernced about the spillover effects of domestic turmoil in China ${ }^{5}$ like the turbulence in the Chinese financial market at the beginning of 2016 .

The focus of this paper is on financial firms because of the importance of the

\footnotetext{
'Source: authors' calculation from the trading data available on the Chinese Dazhihui Securities trading software. The historical daily fluctuation range of the USD to RMB was -2.012 (min) to $1.102(\max )$ with an average of -0.0061 for $01 / 2006-05 / 2015$.

${ }^{4}$ The Yuan was the fourth most widely used currency for international payments in 2015 according to the Society for Worldwide Interbank Financial Telecommunication (SWIFT).

${ }^{5}$ Changes in the RMB exchange rate changes may affect the exports of competitor countries in third markets through the "spillover effect" (Mattoo et al., 2012).
} 
financial sector for the development of any country, and particularly for emerging economies. There is a clear link between economic growth, poverty alleviation and the degree of development of the financial sector (e.g. Cepparulo et al. (2017)). Exchange rate exposure may have dramatic consequences for the development and health of the financial sector in China, and foreign financial flows are an important source of funds for the development of the country. The net financial account for China was positive from 1997 until 2015, but with a clear trend towards negative territory $^{6}$. Financial corporations play a key role in attracting and acting as a channel for foreign inflows of capital. Whether or not they are seen as such depends on how they manage their risk exposure, amongst other factors. Given the internationalisation of the RMB, exchange rate risk management is becoming a priority.

Less attention has been paid in the literature to the currency exposure of Chinese firms. At the industry level, exchange rate movements have significant exposure effects on industry returns, and the exposures vary across industries (Miao et al., 2013; Cuestas and Tang, 2015; Tang, 2015). At the firm level, Li et al. (2015) find that the foreign currency denominated prices of Chinese exporters receive high exchange rate pass-through effects. Wong et al. (2009) suggest that negative foreign exchange exposure is prevalent for larger Chinese banking firms, and a strong correlation between firm size and exposure effects has been found in Chinese firms (Tang, 2015). Regarding asymmetric effects from currency movements, Miao et al. (2013) and Cuestas and Tang (2015) find that asymmetries exist, but they did not examine the determinants of the asymmetric exposures. Dranev and Babushkin (2014) study the asymmetric exchange rate exposure and its determinants in the BRIC (Brazil, Russia, India and China) countries, but they fail to explore the effects of positive and negative exchange rate shocks on firm returns.

Our study fills the gap in the literature. We aim to investigate both the symmetric and asymmetric exchange rate exposures of Chinese financial firms before and after the announcement of RMB internationalisation. The conventional approach for measuring exchange rate exposure is based upon the capital asset pricing model (CAPM) framework (Bodnar and Gentry, 1993; Dominguez and Tesar, 2001; Chue and Cook, 2008). Previous studies find that currency depreciations and appreciations have similar effects in magnitude on firm returns (Bodnar and Wong, 2003;

\footnotetext{
${ }^{6}$ According to data from the World Bank (https://data.worldbank.org/indicator/BN.FIN.TOTL.CD? locations $=\mathrm{CN}$ ), the net financial account became negative for the first time since 1997 .
} 
Dominguez and Tesar, 2006; Muller and Verschoor, 2007; Chue and Cook, 2008), and this is called the symmetric exchange rate exposure. However, currency depreciations may not have the same effects in magnitude on firm values that currency appreciations do, so empirical attention has been paid to modelling the asymmetric effects of exchange rate changes on firm returns (Koutmos and Martin, 2003; Muller and Verschoor, 2006; Koutmos and Martin, 2007; Hsu et al., 2009; Tang, 2015).

This paper follows the CAPM framework but adds a GARCH $(1,1)$ specification to the modelling in order to remove potential $\mathrm{ARCH}$ effects in the regression residuals, which improves the accuracy of the exchange rate exposure measurement. Considering the different effects on firm values during the ups and downs of currency movements, we introduce the nonlinear autoregressive distributed lagged (NARDL) model to explore the long-run asymmetric exchange rate exposure. Besides the commonly used trade weighted effective exchange rate (TWEER) in the literature, we also examine the currency exposure of the bilateral real rate of the USD to the RMB since the Yuan has assigned a heavy weight against the USD in the currency basket. ${ }^{7}$ Further, we explore the determinants of (a)symmetries by examining firm level indicators using quantile regressions.

The results of this study underscore the importance for Chinese financial firms of managing currency exposures. Our main findings can be summarised as follows. First, after the announcement of RMB internationalisation in 2009, an increasing number of Chinese financial firms have become exposed to currency movements, in particular from the negative change in the trade-weighted effective exchange rate. Second, significant estimates of asymmetric exchange rate exposure suggest that before 2009 currency movements increased firm returns because of the strong economic fundamentals in China, while after 2009 the negative TWEER shock dominates in the asymmetric exposures and the positive RER shock plays an important role in influencing firm values. ${ }^{8}$ Third, currency exposures at the firm level are principally associated with total assets, firm size, earnings per share, investment incomes, net cash flows and total liabilities.

The findings of this paper have important policy implications. First, the increas-

\footnotetext{
${ }^{7}$ Research evidence also shows that the Yuan is still mainly pegged to the USD after the 2005 RMB policy reform (Frankel and Wei, 2007).

${ }^{8}$ The negative change in the trade-weighted effective exchange rate means a weaker RMB in the context. While a positive RER shock indicates the weakening of the RMB as well, since the base currency is USD in the bilateral exchange rate of USD/RMB. We use the data and expression of $\mathrm{USD} / \mathrm{RMB}$ for convenience as this is widely adopted by the Chinese authorities.
} 
ingly accelerated pace of RMB internationalisation means the hedging strategies for Chinese firms to offset currency exposures should focus more on a basket of currencies rather than on the USD alone. Moreover, since the asymmetric exchange rate exposure implies that fewer firms can enjoy the benefits of positive unexpected movements in the exchange rate of the RMB, forward or future contracts are more effective tools for firms to hedge currency risks with, rather than option contracts. Last but not the least, in order to regain investment confidence and prevent spillover effects to the global economy, the Chinese authorities should focus on microprudential type policies to protect them from negative movements in exchange rates, and help them enjoy the potential benefits of positive movements. It is quite essential for policy makers to carry out more reforms before allowing the RMB to become fully convertible.

The remaining parts of this paper are organised as follows. An overview of RMB internationalisation is given in Section 2. Section 3 presents the empirical methods for this study. Section 4 describes our data. Section 5 investigates the symmetric and asymmetric exchange rate exposure and the exchange rate exposure determinants at the firm level. The last section concludes.

\section{General Overview of RMB Internationalisation}

The outbreak of the financial crisis from 2008-onwards and the rapid contagion among countries reflect the inherent vulnerabilities and systemic risks in the current international monetary system (Zhou, 2009). Reforms to the international monetary system are improving the valuation and allocation of the special drawing right (SDR), and in March 2009, the People's Bank of China (PBOC) proposed the creation of an international reserve currency that is disconnected from individual countries. This symbolizes the launch of RMB internationalisation. Since then, China has accelerated the pace of RMB internationalisation by establishing dim sum bond markets and expanding projects for cross-border trade settlement in RMB, which have helped in increasing offshore RMB liquidity.

The internationalisation of the RMB requires not only a large and stable home 
economy, but also strong institutional support. ${ }^{9}$ However, the reform of deep, open and well-regulated capital markets is far from complete. For the Yuan to become a more widely held reserve currency, greater access to local capital markets for foreign investors, deeper global RMB liquidity and wider cross-border flow channels should be the priorities of China's reform. Indeed, there are major milestones on the road to RMB internationalisation. The Yuan's daily trading band has been widened to $2 \%$ against the USD. ${ }^{10}$ This lets market power play a big part in determining the RMB exchange rate. In November 2015, the IMF included the Yuan as the fifth member of its SDR currency basket, which marked an important milestone in the integration of the Chinese economy into the global financial system. ${ }^{11}$ By December 2015, China has signed RMB Bilateral Swap Agreements with 33 economic partners and established 15 RMB Offshore Clearing Banks. The RMB Qualified Foreign Institutional Investor (RQFII) programme licences and quotas have also been extended to 15 countries or regions. These movements made the RMB the fourth most widely used world payment currency in August 2015, overtaking the Japanese Yen, and remaining behind only the USD, Euro and Sterling. ${ }^{12}$ The RMB internationalisation and its foreign exchange reforms are moving forward rapidly and a fully convertible RMB could be expected in the next couple of years.

Chinese financial firms are strong promoters of RMB internationalisation. With robust official and institutional support, Chinese financial firms are actively boosting RMB internationalisation through a wide range of activities, including offering overseas loans, investing in the global financial market and issuing offshore RMB bonds. Commercial banks, like the Bank of China (BOC), are the main providers of offshore RMB financial services. The four state-owned banks are designated as RMB

\footnotetext{
${ }^{9}$ The Chinese economy is clearly large relative to others as China has been the second largest importer and the largest exporter in the world since 2009. China has a record of low inflation, small budget deficits and stable growth, which has undoubtedly made the RMB more attractive in recent years. Since the PBOC launched RMB internationalisation in March 2009, the Chinese authorities have been strengthening financial regulation and pushing forward reforms, which give strong institutional support for the approach to RMB internationalisation.

${ }^{10}$ China also announced its intention to expand the Yuan's daily trading band to $3 \%$ against USD in July 2015. Initially, it was widened from $0.3 \%$ (1994) to $0.5 \%$ (2007), $1 \%$ (2012), and $2 \%$ (2014).

${ }^{11}$ The Yuan has a weight of $10.92 \%$ in the basket, lower than that of the USD (41.73\%) and Euro (30.9\%), but higher than that of the Japanese Yen (8.33\%) and British Pound Sterling (8.09\%).

${ }^{12}$ Source: Financial Times news "Renminbi overtakes Japanese Yen as global payments currency, 6 October 2015".
} 
clearing banks so as to establish a global clearing network. ${ }^{13}$ They are also the main underwriters of offshore RMB bonds, i.e., the BOC issued 2.5 billion RMB bonds in London in 2014. Reports show that investment banks, like securities, mutual funds and insurance companies, are accelerating the pace of overseas mergers and acquisitions. Europe has so far been the top investment destination for Chinese investment banks. ${ }^{14}$ Furthermore, other Chinese financial firms, like real estate companies, have seen a better financing and investment environment benefit from the capital account liberalisation and the establishment of offshore RMB hubs. However, economic theory suggests that firm values are exposed to unanticipated changes in the exchange rate (Adler and Dumas, 1984; Jorion, 1990). Our objective in this paper is to explore the currency exposure of Chinese financial firms within the existing Chinese financial system in the context of an accelerated RMB internationalisation.

\section{$3 \quad$ Empirical Strategies}

\subsection{Theoretical Framework}

The most popular approach for measuring exchange rate exposure is built upon the capital asset pricing model (CAPM) (Adler and Dumas, 1984; Bodnar and Gentry, 1993; Dominguez and Tesar, 2001; Martin and Mauer, 2003; Chue and Cook, 2008), which establishes that firm returns are subject to unanticipated changes in exchange rates. The measurement of exchange rate exposure consists of a regression of firm returns on exchange rate changes and market returns. ${ }^{15}$

$$
S R_{i, t}=\beta_{0, i}+\beta_{1, i} E R_{t}+\beta_{2, i} R M_{t}+\varepsilon_{i, t}
$$

Where $S R_{i, t}$ is the stock return for firm $i$ at time $t, E R_{t}$ is the change in the trade weighted real effective exchange rate given that most firms export their products

\footnotetext{
${ }^{13}$ The four state-owned banks are BOC, Agriculture Bank of China (ABC), Construction Bank of China (CBC), and Industrial and Commercial Bank of China (ICBC). The BOC is the global offshore RMB clearing bank in Hong Kong and Shanghai.

${ }^{14}$ Source: China daily "Chinese OBOR-linked investments to boost RMB internationalisation, 02 November 2015."

${ }^{15}$ There are some studies that us the excess returns on firm's closing prices and market portfolios (Chue and Cook, 2008; Du and Hu, 2012). Following Adler and Dumas (1984) and Dominguez and Tesar (2006), and many others, we use the original form of the CAPM in this paper, as Tang (2015) suggests that both the CAPM and the augmented CAPM (measuring excess returns) are appropriate for measuring the currency exposure of Chinese firms. Another reason is that no preferred proxies can be selected for the risk-free rate in China due to the immaturity of the Chinese bond and Shanghai Interbank Offered Rate (Shibor) markets.
} 
to many countries and expose to movements of multiple exchange rates, and $R M_{t}$ is the return on the market portfolio. $\varepsilon_{i, t}$ is an error term. The incorporation of market returns takes into consideration the effects of other macroeconomic variables on realised returns. ${ }^{16}$ The test of exchange rate exposure is to assess the significance of the regression coefficient $\beta_{1, i}$, which represents the residual exposure elasticity of the firm after it is conditioned to the market return. ${ }^{17}$

\subsection{Modelling the Symmetric and Asymmetric Exchange Rate Exposures}

The traditional approach for estimating equation (1) is ordinary least square (OLS), which implies that firm returns respond symmetrically to currency movements, so that the magnitude of the effect is the same regardless of the sign of the shock. However, the hypothesis of constant variance in the model is often rejected for financial time series data like stock returns and exchange rate changes. The presence of heteroskedasticity usually invalidates the test statistics. For this case, we introduce ARCH effects. We run the usual regression (OLS) if we cannot reject the null hypothesis of constant variance. Otherwise, we add a $\operatorname{GARCH}(1,1)$ specification into the market model. The regression model for measuring exchange rate exposure under this condition has the following form:

$$
\begin{aligned}
& S R_{i, t}=\beta_{0, i}+\beta_{1, i} E R_{t}+\beta_{2, i} R M_{t}+\varepsilon_{i, t} \\
& \varepsilon_{i, t}=\mu_{i, t} \times\left(h_{i, t}\right)^{\frac{1}{2}} \\
& h_{i, t}=\delta_{i}+\lambda_{i} \varepsilon_{i, t-1}^{2}+\gamma_{i} h_{i, t-1}
\end{aligned}
$$

Where $h_{i, t}$ represents the conditional variance of the residuals and $\mu_{i, t}$ is the white noise error term. The model presented in equation (2) measures the symmetric exchange rate exposure that reflects the linear adjustment of firm returns to exchange rate shocks. Nonetheless, stock prices may respond asymmetrically to exchange rate

\footnotetext{
${ }^{16}$ This approach is preferred by many economists, notably Jorion (1990), Williamson (2001) and Dominguez and Tesar (2006). This model also avoids the issue of endogeneity as firm returns cannot affect exchange rate changes and market returns.

${ }^{17}$ Early studies do not include the return on market portfolio, so the coefficient $\beta_{i, t}$ is referred to as total exposure. This approach cannot distinguish the different effects of exchange rate movements and the impact of macroeconomic shocks that affect firm values and exchange rates (Dominguez and Tesar, 2006).
} 
changes. This means that currency depreciations may have a different impact on firm returns in magnitude to that of currency appreciations. Therefore, researchers are increasingly shifting their attention to modelling asymmetric exchange rate exposure (Muller and Verschoor, 2006; Chkili et al., 2012). However, these studies fail to explore either the long-run or short-run effects of currency movements. In this paper, we introduce the nonlinear autoregressive distributed lag (NARDL) model (Shin et al., 2014) to explore both the long-run and short-run effects of exchange rate changes. The basic form of the asymmetric long run regression is described as:

$$
S R_{i, t}=\alpha_{0, i}+\beta_{i}^{+} E R_{t}^{+}+\beta_{i}^{-} E R_{t}^{-}+\gamma_{i}^{+} R M_{t}^{+}+\gamma_{i}^{-} R M_{t}^{-}+\varepsilon_{i, t}
$$

Where $E R$ is decomposed into $E R^{+}$and $E R^{-}, E R_{t}=E R_{0}+E R_{t}^{+}+E R_{t}^{-}$, where $E R_{t}^{+}$and $E R_{t}^{-}$are partial sum processes of positive and negative changes in $E R_{t}$, respectively. $E R_{t}^{+}=\sum_{j=1}^{t} \Delta E R_{j}^{+}=\sum_{j=1}^{t} \max \left(\Delta E R_{j}, 0\right), E R_{t}^{-}=\sum_{j=1}^{t} \Delta E R_{j}^{-}=$ $\sum_{j=1}^{t} \min \left(\Delta E R_{j}, 0\right) . \quad R M$ is decomposed into $R M^{+}$and $R M^{-}$, respectively. In this case, $R M_{t}$ is decomposed on the same basis. The error correction form of the NARDL $(\mathrm{p}, \mathrm{q})$ model is described as follows:

$$
\begin{aligned}
\Delta S R_{i, t}= & \rho S R_{i, t-1}+\theta^{+} E R_{t-1}^{+}+\theta^{-} E R_{t-1}^{-}+\lambda^{+} R M_{t-1}^{+}+\lambda^{-} R M_{t-1}^{-}+\theta_{\omega} \omega_{t-1}+ \\
& \sum_{j=1}^{p-1} \gamma_{j} \Delta S R_{t-j}+\sum_{j=0}^{q-1}\left(\pi_{j}^{+} \Delta E R_{t-j}^{+}+\pi_{j}^{-} \Delta E R_{t-j}^{-}+\Psi_{j}^{+} \Delta R M_{t-j}^{+}+\right. \\
& \left.\psi_{j}^{-} \Delta R M_{t-j}^{-}+\omega_{w, j} \Delta w_{t-j}\right)+\varepsilon_{i, t}
\end{aligned}
$$

Where $\beta_{i}^{+}=-\theta^{+} / \rho$ and $\beta_{i}^{-}=-\theta^{-} / \rho$ are the asymmetric long run exchange rate exposure coefficients. $\gamma^{+}=-\lambda^{+} / \rho$ and $\gamma^{-}=-\lambda^{-} / \rho$ are the asymmetric long run elasticities for market returns. $\omega_{t-1}$ is a $k \times 1$ vector of regressors entering the model symmetrically. ${ }^{18}$ In this paper, we are interested in the long run positive and negative exchange rate coefficients to measure the degree of asymmetric effects $\left(\beta_{i}^{+}-\beta_{i}^{-}\right)$.

\footnotetext{
${ }^{18}$ The NARDL model can easily be estimated by OLS irrespective of the integration orders of variables (Greenwood-Nimmo and Shin, 2013; Shin et al., 2014). In this study, we are mainly interested in the long run $\beta$ s, and therefore unrestricted NARDLs are estimated.
} 


\subsection{Exploring Symmetric and Asymmetric Exchange Rate Exposure Determinants}

Firm returns may be exposed to symmetric or asymmetric exchange rate exposures according to equations (2)-(4). Intuitively, it would seem wise to explore further the symmetric and asymmetric exchange rate exposure determinants. Can they be explained from the nature of firm activities at the micro level? To address this issue, we construct a model for interpreting exchange rate exposure determinants by incorporating a group of firm characteristics.

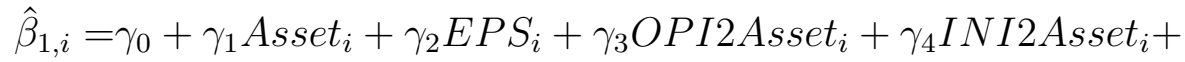

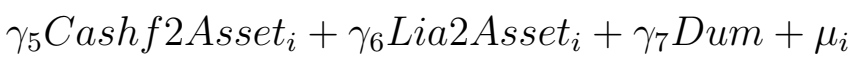

$$
\begin{aligned}
& \left(\hat{\beta}_{i}^{+}-\hat{\beta}_{i}^{-}\right)=\gamma_{0}+\gamma_{1} \text { Asset }_{i}+\gamma_{2} \text { EPS }_{i}+\gamma_{3} \text { OPI } 2 \text { Asset }_{i}+\gamma_{4} \text { INI }_{2} \text { Asset }_{i}+ \\
& \gamma_{5} \text { Cashf } 2 \text { Asset }_{i}+\gamma_{6} \text { Lia } 2 \text { Asset }_{i}+\gamma_{7} \text { Dum }+\mu_{i}
\end{aligned}
$$

Equations (5) and (6) are models for exploring symmetric and asymmetric exchange rate exposure determinants respectively. Where $\hat{\beta}_{1, i}$ is estimated from equation (2). $\hat{\beta}_{i}^{+}$and $\hat{\beta}_{i}^{-}$are estimated from equation (4). Asset ${ }_{i}$ is the total assets of each firm. EPS $S_{i}$ indicates the firm's earnings per share. OPI2Asset i $_{i}$ measures the main business operating income to total assets ratio. INI2Asset ${ }_{i}$ and Cashf 2 Asset $_{i}$ are the ratios of investment incomes to total assets and net cash flows to total assets, respectively. Lia2Asset L $_{i}$ denotes the ratio of total liabilities to total assets. Dum is a dummy variable indicating the firm size. Dum equals 1 if the average total assets is greater than 7 billion RMB (more than 1 billion USD), zero otherwise. These firm characteristics reflect the firm's intrinsic response to currency movements at the micro level (Chue and Cook, 2008; Acharya and Steffen, 2015). ${ }^{19}$

To classify different degrees of exposure that might be related to different firm characteristics, the econometric method used for modelling the determinants of exchange rate exposure in this paper is quantile regressions (Koenker and Bassett Jr, 1978; Buchinsky, 1995). The conditional quantile regression model can be expressed as:

\footnotetext{
${ }^{19}$ Following Chue and Cook (2008) and Acharya and Steffen (2015), we select a group of firm level indicators to explore the determinants of currency exposures. The variables used in this study depend on the availability of relevant data.
} 


$$
Q_{\theta}\left(y_{i} \mid x_{i}\right)=x_{i}^{\prime} \beta_{\theta}, \quad i=1, \ldots, n
$$

Where $x_{i}$ and $\beta_{\theta}$ are $k \times 1$ vectors. The disturbance term $\mu_{\theta}=y-x^{\prime} \beta_{\theta}$ is assumed to have a continuously differentiable cumulative distribution function (CDF), $F_{\mu_{\theta}}(\cdot \mid x)$ and a density function $f_{u_{\theta}}(\cdot \mid x)$. An estimator of $\beta_{\theta}$ is used to minimise the following function:

$$
\min _{\beta} \frac{1}{n} \sum_{i=1}^{n} \rho_{\theta}\left(y_{i}-x_{i}^{\prime} \beta\right)
$$

Where $\rho_{\theta}(\lambda)=(\theta-I(\lambda<0))$ is referred to as the check function and $I(\cdot)$ is the indicator function. ${ }^{20}$ The minimisation problem is set up as a linear programming problem that can be solved with linear programming techniques, as suggested by Koenker and Bassett Jr (1978) and Koenker (2005).

\section{Data Description}

\subsection{Stock Returns and Exchange Rate Changes}

We obtain the monthly closing prices of Chinese financial firms from the Wind Financial Terminal (WFT) database. ${ }^{21}$ Our initial sample contains 209 financial firms over a period spanning from January 1994 to July 2015. ${ }^{22}$ The sample period is selected by taking the earliest available date for the TWEER. ${ }^{23}$ The TWEER is widely used in the literature for measuring exchange rate exposure as firm values are exposed to movements of multiple currencies rather than the dominant currency USD. The TWEER is available on the website of the Bank for International Settlements (BIS). As the Chinese currency is still predominantly pegged to the USD after the 2005 RMB policy reform (Frankel and Wei, 2007), we also investigate the responsiveness of firm values to changes in the real rate of USD/RMB (units of RMB

\footnotetext{
${ }^{20}$ The slope of $\rho_{\theta}(\lambda)$ is $\theta$ when $\lambda>0$ and is $\theta-1$ when $\theta<0$, but is undefined for $\theta=0$, see (Wooldridge, 2010, p.450) for more details. Choosing the $\hat{\beta}_{\theta}$ that minimise $\rho_{\theta}(\lambda)$ is equivalent to finding the $\hat{\beta}_{\theta}$ that makes $x \hat{\beta_{\lambda}}$ best fit the quantiles of the distribution of $y$ conditional on $x$.

${ }^{21}$ Financial firms in the WFT database include banking, securities, insurance, investment and real estate companies, and those enterprises with main business operations in the real estate industry, such as China Enterprise and China Merchants Property.

${ }^{22}$ Monthly data are used as China implements a managed floating exchange rate policy and the RMB daily trading band is restricted. Investors could foreseen the degree of currency exposures at the daily horizon since the daily fluctuation range is within their expectations.

${ }^{23}$ The earliest available date for the TWEER is January 1994.
} 
Figure 1: Exchange Rate Series
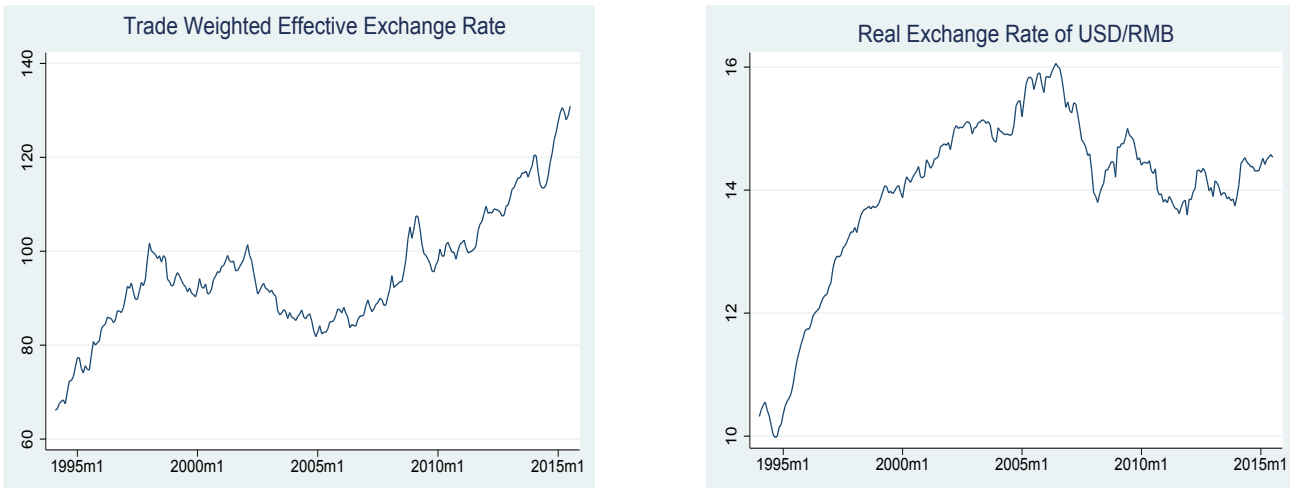

per USD). The monthly bilateral rate for USD/RMB is collected from the People's Bank of China (PBOC). To calculate the real exchange rate, the US and Chinese CPIs are obtained from the US Bureau of Labor Statistics and National Bureau of Statistics of China respectively. ${ }^{24}$

Figure 1 gives plots of exchange rates. The left panel exhibits the real rate of the trade weighted effective exchange rate. It shows that the overall purchasing power of the Chinese currency has been strengthening against its trading partners, although there was a slowdown during the 2008 global financial crisis. The right panel represents the real exchange rate USD/RMB, and it reveals that the Yuan was depreciating relative to the USD before the crisis. After the crisis, the Yuan's exchange rate tends to be relatively stable and fluctuates within a small range.

Table 1 reports summary statistics for stock returns and exchange rate changes (see panel A). ${ }^{25}$ Our final sample consists of 203 Chinese financial firms, of which 16 are banking firms, 15 are $B$ share financial firms, and 172 are other financial firms, most of them are real estate firms. ${ }^{26}$ We categorize these financial firms in different groups, as banking firms and $B$ share financial firms have different properties. The growing internationalisation of Chinese banks in both their fundraising activities and banking businesses may suggest that these banks in general have become increasingly exposed to currency risks (Wong et al., 2009). In addition, B

${ }^{24}$ The real exchange rate of USD/RMB is defined as the nominal exchange rate adjusted for foreign and domestic prices, $R E R_{t}=N E R_{t} \frac{P_{t}^{*}}{P_{t}}, R E R_{t}$ and $N E R_{t}$ are the real and nominal exchange rate of USD/RMB respectively. $P_{t}^{*}$ and $P_{t}$ are the CPI of US and China respectively.

${ }^{25}$ Simple arithmetic returns rather than logarithmic returns are adopted in this study, as the mean of a return set calculated using logarithmic returns is less than the mean calculated using simple returns by an amount related to the variance of the set. The table also shows that most variables are not normally distributed. Firm returns are defined as: $S R_{t}^{i}=\frac{p_{t}^{i}-p_{t-1}^{i}}{p_{t-1}^{i}}$. The change in the exchange rate is constructed on the same basis: $E R_{t}^{i}=\frac{e r_{t}^{i}-e r_{t-1}^{i}}{e r_{t-1}^{i}}$.

${ }^{26}$ The final sample meets the requirement of a minimum of 40 observations for each firm. 
share financial firms in the Chinese stock market are traded in the USD. This may indicate that exposures of $B$ share financial firms are more likely to be caused by the movement in the USD. Therefore, we would expect that the two types of financial firms may receive different levels of currency exposures. The first four rows give the descriptive statistics of the breakdown of different types of financial firms and all firms. Relatively speaking, bank returns exhibit less volatility than the returns of $B$ share and other financial firms. Four out of sixteen of the bank returns are normally distributed. Market returns have similar characteristics to bank returns, but the Jarque-Bera (JB) asymptotic test for normality rejects the null hypothesis. The movements of the real exchange rate (RER) of USD/RMB demonstrate fewer fluctuations than that of the TWEER, which could be explained by the close monitoring by the authorities on the bilateral rate of USD/RMB and the heavy weight placed on the USD.

\subsection{Firm Characteristics}

Firm level explanatory variables are obtained from the NetEase online stock database. Panel B of Table 1 reports summary statistics of firm characteristics. ${ }^{27}$ Subject to data availability, we select six variables from firm financial statements. The first variable is firm total assets. We also control for firm size by adopting a dummy variable, see equations (5)-(6), as large firms are more likely to be subject to currency exposures. In addition, large firms are more likely to hedge their foreign exchange risks if they have already focused on this and set up special department for that purpose. EPS measures the portion of a firm's profit allocated to each outstanding share of common stock and serves as an indicator of a firm's profitability. The remaining four variables are measured in ratios relative to total assets over the period 1990q4-2015q2, but the availability of the first financial statements for some newly listed financial firms varies in our sample, and the youngest firm released its first financial statements in $2006 \mathrm{q} 4$, for instance. OPI2Asset is the main business operating income to total assets ratio, indicating the profitability of a firm's operating activities. INI2Asset reflects the ratio of investment incomes to total assets. Cashf2Asset indicates the ratio of net cash flows to total assets, which refers to the change in a firm's cash balance during each reporting period that may be partially

\footnotetext{
${ }^{27}$ The descriptive statistics of the original data like 'total assets' are reported in Table 1, while we use natural log of total assets in the empirical modelling section.
} 
related to foreign transactions. ${ }^{28}$ The last variable is Lia2Asset, which measures the ratio of total liabilities to total assets. All firm level explanatory variables are measured as time-series averages, rather than observations at a certain point in time (Chue and Cook, 2008).

\section{$5 \quad$ Empirical Results}

\subsection{Symmetric Exchange Rate Exposure}

We estimate equation (1) by firm using OLS and report the results in Table 2. If $\mathrm{ARCH}$ effects exist in the residuals of the symmetric exchange rate exposure estimates, we add a $\operatorname{GARCH}(1,1)$ specification to the model and estimate equation (2). The sample period is divided before and after the announcement of the launch of RMB internationalisation by the PBOC in March 2009. ${ }^{29}$ Given the fact that different financial firms may behave differently in response to currency movements, we report estimation results from banking firms, $B$ shares and other financial firms separately. Before March 2009, ${ }^{30}$ the average exchange rate exposures for banks, B shares and other financial firms are $-0.653,-0.397$ and 0.148 respectively, indicating that a $1 \%$ appreciation in the TWEER is associated with declines of firm returns by $65.3 \%$ and $39.7 \%$ for banks and $B$ shares, but with a $14.8 \%$ rise in the returns for other financial firms. When exposures to the change in the RER are measured, the average exposure coefficients for banks, $B$ shares and other financial firms are $1.215,-1.798$ and 0.454 , respectively, which are much bigger in magnitude than the estimates for TWEER changes. This could be explained by the fact that Chinese financial firms are more likely to be exposed to the bilateral real exchange rate of USD/RMB before the launch of RMB internationalisation, although the 2005 RMB policy reform started the Yuan's era with reference to a basket of currencies. It is supported by the evidence that the Chinese currency was still pegged to the USD (Frankel and Wei, 2007).

Insert Table 2 about here.

\footnotetext{
${ }^{28}$ This might be further related to the transaction and translation exposure.

${ }^{29}$ We estimate the GARCH model with a minimum requirement of 40 observations. If the sample does not meet this requirement, equation (2) is estimated by OLS.

${ }^{30}$ In order to get a clear picture on the mean exposure changes before and after the RMB internationlisation, we divide the sample into before and after March 2009 subsamples rather than including an interaction dummy variable.
} 
Compared to the estimates from the pre-launch RMB internationalisation subsample, the average currency exposures of Chinese financial firms clearly increase significantly in response to the change in the TWEER in the post-launch RMB internationalisation subsample. The estimates for banks, $B$ shares and other financial firms are $-1.042,-1.575$ and -1.766 respectively. Testing the effect from RER movements show the exposure coefficients for banks (-0.12) and $B$ shares (-0.35) decline dramatically. The average exposure coefficient for other financial firms (0.779) during this period is greater than that of the pre-launch period at $32 \%$, which is still much smaller than the exposure to TWEER changes in magnitude. It shows that Chinese financial firms are in fact participating in the global market and are exposed to the movements of multilateral exchange rates. ${ }^{31}$

The estimates from the whole sample period are generally consistent with the results from the samples from before and after 03/2009 (columns 2-5). The results reported in the last two columns show that banking firms are more likely to be exposed to the change in the TWEER, and $B$ shares are mainly subject to exposures from RER changes. In both cases, currency movements have a negative impact on firm returns. However, the estimates from panels C\&D in the last two columns do not exhibit significant difference in the average exposure coefficients in terms of sign and magnitude, since the effects from the positive and negative exposures cancel each other out.

Interestingly, most of the average exposure coefficients are negative for TWEER but positive for RER. ${ }^{32}$ This is due to their different measurements, but both indicates a weaker RMB. ${ }^{33}$ The TWEER represents the purchasing power of one currency. An increase in the TWEER implies the strength of the domestic currency against the main trading partners, benefiting imports, but undermines the competitiveness of exports, which in turn affects the returns of stock prices. As the upturn in the RER means a depreciation of the Chinese currency, i.e., a weaker RMB, it

\footnotetext{
31 The 2008 US subprime crisis caused spillover effects to the world economy and the Chinese economy is no exception. Chinese financial firms have to seek overseas investment opportunities to maintain a stable growth. Apparent examples are overseas mergers and acquisitions of these firms in recent years and consequently they are increasingly exposed to TWEER changes.

${ }^{32}$ The sign of the average exposure coefficients estimated from $B$ shares (panel B) is negative, since $B$ shares are traded in USD and the upturn of RER indicates the appreciation of USD, which reduces the returns of $B$ shares. This is different from the estimates of other panels, as shares of other firms in our sample are traded in RMB.

${ }^{33}$ The TWEER is collected from the Bank for International Settlement (BIS), and the exchange rate of USD/RMB is collected from the People's Bank of China (PBOC). To maintain the original data format and meaning, we do not make any changes to the data.
} 
strengthens the competitiveness of exports and further raises firm returns.

The symmetric exchange rate exposure estimates reveal that regression residuals show evidence of heteroskedasticity (see $A R C H_{N o}$. for each panel). The average $R^{2}$ is also reported for each panel, which is quite small and can hardly explain the goodness of model fit. This makes us question the appropriateness of symmetric exchange rate exposure modelling. A further step should be an investigation of asymmetric exchange rate exposure, since financial firms may behave differently in response to the ups and downs in exchange rates.

\subsection{Asymmetric Exchange Rate Exposure}

Table 3 reports summaries of the asymmetric exchange rate exposure estimates. We again separately estimate the pre- and post-launch RMB internationalisation periods for different types of Chinese financial firms ( banks, $B$ shares and other financial firms). We estimate the unrestricted NARDL model adopting the lag structure $p=q=4$ for all firms as it suffices to whiten the residuals. ${ }^{34}$ This table reports the long-run exchange rate exposure coefficients with diagnostics as we are only interested in the long-run impact of exchange rate changes on firm values.

Insert Table 3 about here.

For banking firms (panel A), both the pre- and post-launch RMB internationalisation subsample estimates reveal that bank returns are subject to asymmetric exchange rate exposure effects, as demonstrated by the asymmetry test $\left(\beta^{+}-\beta^{-}\right){ }^{35}$ The long-run coefficients for positive and negative TWEER shocks are 3.618 and 2.968, respectively. ${ }^{36}$ It can be interpreted that an upturn of $26.74 \%$ in TWEER movements increases bank returns by $1 \%$, while a downturn of $33.69 \%$ achieves the opposite. In response to RER changes, the long run coefficients are -2.681 and -4.059 for positive and negative RER shocks, respectively. ${ }^{37}$ This means that an increase of $37.3 \%$ in RER returns decreases bank returns by $1 \%$, while a decline of $24.64 \%$ achieves the opposite result. Furthermore, the evidence strengthens when we esti-

\footnotetext{
${ }^{34}$ Brun-Aguerre et al. (2015) suggest that imposing long run symmetry may lead to biases in estimation and inference. As reported in Table 3, a majority of the estimates do not have serial correlated residuals and ARCH effects. Inferences are based on OLS standard errors for all firms.

${ }^{35}$ In panel A, N equals 5 (5 banking firms) in the pre-2009 sample as we exclude those firms with fewer than 40 observations.

${ }^{36}$ Positive TWEER shocks indicate the appreciation of RMB, i.e., a stronger RMB, and vice versa. Hereafter the same meaning applies

${ }^{37}$ Positive RER shocks indicate the depreciation of RMB, i.e., a weaker RMB, and vice versa.Hereafter the same meaning applies.
} 
mate the NARDL model using the post-launch RMB internationalisation subsample (after 03/2009). An increasing number of banking firms suffer asymmetric exposure from TWEER changes. This seems to imply that banks have been lacking the management of asymmetric currency exposures after the PBOC's announcement of RMB internationalisation. Note that the PSS F-test accepts the null hypothesis of no long-run equilibrium, which might be due to the unrestricted NARDL estimated or to the small sample used in this study. This is evidenced by the whole sample estimates (the last two columns of panel A) that four of the test reject the null of no long run equilibrium (in response to TWEER changes). The estimates reveal that bank returns are more likely to be exposed to TWEER changes, but this is not conclusive due to the small sample size.

In panel $\mathrm{B}$, asymmetric exchange rate exposures do not exist in $B$ shares, and the PSS F-test also tends to accept the null of no long run relationship in the pre-2009 sample. This is due to a pegged exchange rate policy in China. Foreign capital share ( $B$ shares) returns react symmetrically to the change in the USD. After 2009, the number of firms exposed to asymmetric exposure from TWEER changes increases. A majority of $B$ share returns suffer significant asymmetric effects from RER shocks. The long run coefficients for positive and negative RER changes are -0.245 and -1.307 , respectively. This reveals that the negative RER shock dominates the impact on $B$ share returns. Downward pressure on RER, from RMB appreciation for instance, may decrease the returns of $B$ share financial firms.

For other financial firms (panel C), asymmetric exposures from TWEER changes decline after 2009, both in the number of firms and the magnitude of asymmetric effects. Nonetheless, the exposure betas are negative, indicating that firms are increasingly subject to negative effects from TWEER movements. For both subsample periods, the negative TWEER shock dominates the asymmetric effect, but the positive RER shock (2.732) demonstrates a much stronger impact on firm returns in the post-launch RMB internationalisation subsample. This is reasonable since negative TWEER changes indicate the depreciation of the Yuan but positive RER shocks mean the depreciation of the Yuan. A depreciated currency usually increases domestic firm returns.

The last panel reports the estimation results from the whole sample of financial firms. A number of firms, 36 out of 168, are subject to asymmetric effects from TWEER changes before 2009. The long-run coefficients for positive and negative 
TWEER changes are 3.511 and 3.433 respectively. We can conclude that an upturn of $28.48 \%$ in TWEER changes increases firm returns by $1 \%$ and a downturn of $29.13 \%$ achieves the opposite. However, the two long-run coefficients are negative in the post-launch RMB internationalisation subsample, at -0.552 and -1.605 , suggesting that the increase in the purchasing power of the RMB decreases firm returns. As for RER shocks, the asymmetric positive effect from depreciation goes up significantly after 2009 and helps enhance firm returns.

In general, the asymmetric exchange rate exposure estimates reveal that before the announcement of RMB internationalisation in March 2009, Chinese financial firms were subject to asymmetric TWEER shocks that helped increase firm returns. Before 2009, the Chinese economy enjoyed a higher annual growth rate of nearly $10 \%$ on average, which provided strong support to financial firms through the economic fundamentals in the capital market. A stronger RMB does not undermine China's exports during that period. After 2009, China's growth has slowed down, especially in recent years. The Yuan's overseas expansion exposes Chinese financial firms to multiple currencies and firm returns deteriorate. During the ups and downs of TWEER movements, negative TWEER shocks which mean the depreciation of RMB dominate the impact on firm returns. Interestingly, many financial firms also receive asymmetric effects from RER changes, and the positive RER shock resulting from a weaker RMB plays a major role in affecting firm returns. This indicates that the internationalisation of the RMB is still at its preliminary stage, and capital movements are mainly transacted in USD. Another possible reason is that the Chinese authorities assign a heavier weight to the USD than to other currencies, although the Yuan's exchange rate is said to refer to a basket of currencies.

\subsection{Investigating Determinants of Exchange Rate Exposure}

The previous two subsections reveal that firm values might be exposed to symmetric or asymmetric exchange rate exposures. We shall now proceed to investigate how firm characteristics can be used to explain the responsiveness of firm values to currency movements. The existing theory suggests that large firms are more likely to be exposed to currency movements (Bodnar and Wong, 2003; Huffman et al., 2010). Nevertheless, can the linkage between firm size and currency exposure be explained by firm characteristics like total assets, net cash flows or any other factors? There- 
fore, the following subsections are investigating the potential firm level indicators that relate to different degrees of currency exposures.

The exploration of exchange rate exposure determinants in this study is accomplished by using quantile regressions of exposure betas conditional on a group of firm level indicators. Table 4 reports quantile regression estimates for the determinants of symmetric exchange rate exposure. The results for the 25th, 50th and 75th quantiles of exposure betas conditional on firm characteristics are reported separately. Linktest is used to test if the prediction squared has no explanatory power (model specification indicator).

Before the announcement of RMB internationalisation, the results show that six firm indicators are associated with symmetric TWEER exposure, including the firm's total assets, the square of total assets $(T A \times T A)$, EPS, the investment incomes to total assets ratio, the total liabilities to total assets ratio and firm size. These are the main determinants for dispersing asymmetries. These determinants at the three quantiles estimated are quite different in their signs and magnitudes, with total assets, $T A \times T A$ and INI2Asset for example. The Coef Equal test is rejected, which means that different sets of coefficients are not equal at the three quantiles estimated. Therefore, we can interpret the results from different quantiles of the TWEER exposure distribution, for instance, the firm's total assets are positive and significant at the left tail of the TWEER change distribution, but negative and significant at the right tail, indicating that higher total assets alleviate the firm's exposure to TWEER changes for firms facing higher symmetric TWEER exposure. As the estimated coefficients are different at all three quantiles, we may take the median estimates as an example for interpreting the determinants of symmetric exchange rate exposure. At the 50th quantile, the estimated coefficients for total assets and INI2Asset are -0.257 and -3.031 respectively. This means that a $1 \%$ increase in the firm's total assets decreases symmetric exchange rate exposure by $0.257 \%$, and a $1 \%$ upturn in INI2Asset contributes to a $3.031 \%$ decline in exposure. Furthermore, firm size exhibits positive impact on symmetric exchange rate exposure.

Examining RER changes in response to the potential determinants shows that total assets, $T A \times T A$ and firm size determine the exposure at the 25th quantile. At the median and higher quantiles, the main business operating income to total assets ratio (OPI2Asset), investment incomes to total assets ratio (INI2Asset) 
and total liabilities to total assets ratio (Lia2Asset) are the main drivers determining the symmetric exchange rate exposure. Although the Linktest does not show misspecification of these models, the Coef Equal test is accepted, which means that the coefficients are equal at the three quantiles estimated. Therefore, the median quantile estimates can be used to interpret the exposure determinants, for instance, a $1 \%$ upturn in the main business operating income to total assets ratio increases the symmetric exchange rate exposure by $0.998 \%$.

\section{Insert Table 4 about here.}

After March 2009, the quantile regression estimates imply that total assets, EPS, OPI2Asset, Cashf2Asset and Lia2Asset determine the symmetric exchange rate exposure from TWEER changes. The Linktest indicates misspecification of the lower and median quantile estimates, which implies that the prediction squared would have explanatory power. ${ }^{38}$ The Coef Equal cannot reject the null of equal coefficients in the three quantiles estimated. This means that only the firm's total assets and the ratio of total liabilities to total assets (Lia2Asset) have a significant impact on the symmetric exposure. In terms of the magnitude, it can be explained that a $1 \%$ increase in total assets raises symmetric exchange rate exposure by $0.124 \%$, but a $1 \%$ upturn in the Lia2Asset decreases the exposure effects by $1.332 \%$. The results show inconsistence compared to the estimates from the prelaunch RMB internationalisation subsample. This suggests that firm characteristics may be positively or negatively related to currency movements. Three indicators for the symmetric exposure determinants relating to RER changes, namely total assets, EPS and Lia2Asset, are significant at the 50th or 75th quantiles or both, but the null of equal coefficients at the three quantiles estimated is accepted, see Coef Equal. This means that only the firm's EPS and Lia2Asset determine the symmetric exposure from RER changes. Furthermore, the Linktest is accepted at the 25th and 50th quantiles, which indicates the good performance of the estimates.

Table 5 reports quantile regression estimates for the determinants of asymmetric exchange rate exposure. Before the launch of RMB internationalisation, a firm's total assets and EPS played a key role in determining the asymmetric exposure from TWEER changes, since the Coef Equal test accepts the null of equal coefficients at the three quantiles estimated. These models are well-specified as demonstrated by

\footnotetext{
${ }^{38}$ We tried to include the square of total assets, OPI2Asset, Cashf 2 Asset or Lia2Asset in the regression model, but none of these terms improves the model specification. Therefore, we report the original quantile regression estimates without including any squared terms.
} 
the Linktest. The results reveal that a $1 \%$ increase in total assets widens the degree of asymmetric exchange rate exposure by $0.092 \%$, while an upturn of EPS by $1 \%$ increases asymmetric exchange rate exposure by $0.4 \%$. Regarding to the asymmetric RER exposure determinants, EPS, Cashf2Asset and firm size are the main drivers affecting the asymmetric exchange rate exposure. It suggests that a $1 \%$ upturn in the net cash flows to total assets ratio increases asymmetric RER exposure by 4.694\%. As the null of equal coefficients at the three quantiles estimated is rejected, this implies that lower EPS and Cash f2Asset disperse the firm's exposure to RER changes so that the firm faces lower asymmetric RER exposure at the left tail of the RER exposure distribution. While higher EPS and firm size (large firms) are alleviating the firm's exposure to RER changes for firms facing higher asymmetric RER exposure at the right tail.

\section{Insert Table 5 about here.}

In the post-launch RMB internationalisation subsample, the square of total assets $(T A \times T A)$ is included in the equation for the 25 th and 75 th quantiles to improve the model performance. The quantile regression estimates reveal that firm size is the only factor affecting asymmetric exchange rate exposure from TWEER changes. This is consistent with previous studies in which firm size matters as an important factor for the presence of exchange rate exposure (He and $\mathrm{Ng}, 1998$; Nucci and Pozzolo, 2001; Bodnar and Wong, 2003), since larger firms usually have more overseas operations. They are mainly exposed to two types of currency exposures: transaction exposure and translation exposure. When it comes to the asymmetric exposure from RER changes, Cashf2Asset and Lia2Asset are the major determinants as revealed by the median quantile estimates, since the Coef Equal test cannot reject the null of equal coefficients at the three quantiles estimated. The estimates reveal that a $1 \%$ upturn in the Cash $f 2$ Asset increases asymmetric exchange rate exposure by $7.495 \%$, while a $1 \%$ increase in the Lia2 Asset decreases asymmetric exchange rate exposure by $1.393 \%$. A firm's net cash inflows measure the periodic usage of money in the form of cash during its operations processes. The larger the ratio of net cash flows to total assets, the larger the amount of cash being used during each accounting period. There is no doubt that firms are subject to currency risks during the transaction process. Nevertheless, the Lia2Asset measures a firm's liabilities to be paid to other institutions or individuals in a given period of time, but does not involve any cash transactions. Therefore it reduces the degree of asymmetric 
exchange rate exposure to some extent.

Generally speaking, the pre-launch RMB internationalisation subsample estimates reveal that symmetric exchange rate exposure from TWEER movements is associated with a group of firm level indicators, including total assets, $T A \times T A$, EPS, INI2Asset, Lia2Asset and firm size, and the determinants vary at different exchange rate exposure distribution quantiles estimated. The results also suggest that OPI2Asset, Lia2Asset and firm size are the main factors that affect the asymmetric exposure from RER changes. The findings from the post-launch RMB internationalisation subsample show that total assets and Lia2Asset play important roles in determining the symmetric exposure from TWEER movements. The evidence also reveals that symmetric RER exposure is related to firms' EPS and the ratio of total liabilities to total assets (Lia2Asset). When it comes to the determinants of asymmetric exchange rate exposure, total assets and EPS exhibit major effects on asymmetric TWEER exposure before March 2009, while the asymmetric effects from RER changes are mainly affected by EPS, Cashf2Asset and firm size during the same period of time although the determinants tend to be slightly different in the three quantiles estimated. Furthermore, firm size is the key driver that relate to the asymmetric exchange rate exposure from TWEER movements after March 2009. The asymmetric exposure from RER changes, however, is mainly affected by firm size and Lia2Asset over the same sample period.

\section{Conclusions}

In this paper we examine both the symmetric and asymmetric exchange rate exposures of Chinese financial firms in the context of an accelerated pace of RMB internationalisation. The symmetric exchange rate exposure estimates reveal that an increasing number of Chinese financial firms are suffering negative effects from TWEER movements due to a weaker RMB after the launch of RMB internationalisation, while the number of firms that subject to positive exposures is decreasing dramatically. Comparatively speaking, the numbers of firms with either positive or negative exposure coefficients remain relatively constant in response to RER movements. This implies that after 2009 Chinese financial firms are increasingly exposed to currency exposures, which predominantly come from the change in the TWEER rather than the bilateral real rate of USD/RMB, even though the authorities place 
a heavy weight on the USD in the currency basket.

From the NARDL estimation results, we find that the movement in the TWEER does not decrease firm returns before 2009 as China maintains a high average annual growth rate, which stimulates the capital market in terms of economic fundamentals. After 2009, the Chinese economy gradually slows down. Chinese financial firms face exposures from TWEER changes that mainly decrease firm returns, which are dominated by the negative TWEER shock(a weaker RMB). With regard to the asymmetric effects from RER movements, a peg to the USD policy before 2009 exposed Chinese financial firms to serious negative exposures, especially for banking and $B$ share financial firms. However, after the announcement of RMB internationalisation, the upturn in the RER or a depreciation of RMB increases firm returns as positive RER shocks dominate the asymmetric effects. This suggests that these firms are participating in the RMB internationalisation process and the depreciation of the Yuan helps to increase firm returns.

Furthermore, analysis of the determinants of exchange rate exposure suggests that before 2009 the symmetric and asymmetric exchange rate exposures were mainly associated with total assets, EPS, INI2Asset, Cashf2Asset, Lia2Asset and firm size at the firm level, although the results vary depending on the types of exchange rates and the exchange rate exposure distribution quantiles selected in the model. Nonetheless, EPS (for RER only) and Lia2Asset are key drivers affecting symmetric exchange rate exposure, while firm size (for TWEER only), Cash f 2 Asset (for RER only) and Lia2Asset (for RER only) play important roles in determining asymmetric exchange rate exposure in the post-launch RMB internationalisation subsample.

From a policy perspective, our findings suggest firm managers set up relevant risk management department to hedge currency exposures so as to maintain stable firm returns, and specially the target should be focused on a basket of currencies rather than on the USD alone. Both domestic and foreign investors and clients should pay close attention to the variation in the RMB exchange rate to guard against potential losses caused by symmetric or asymmetric exchange rate exposures arising from currency depreciations and appreciations, since the Chinese authorities are pushing the RMB internationalisation and a fully flexible and convertible RMB can be expected in the coming years. On the other hand, the Chinese government needs to take into consideration the immaturity of the domestic financial markets, setting 
up the relevant risk management mechanism and picking the appropriate time to free-float the RMB in the foreign exchange market, in order to protect the Chinese economy from a hard landing and help restore confidence in investors, which could also reduce spillover effects to the global economy.

In particular, the authorities should focus on microprudential policies to protect firms from negative movements in exchange rates and help them enjoy the potential benefits of positive movements, with the aim of increasing the number of firms who can thus benefit. Since the asymmetric behaviour of the relationship implies from the managerial or firm-level point of view that fewer firms can enjoy the benefits of positive unexpected movements in the exchange rate of the RMB, firms should focus on hedging risks using forward or future contracts, which tend to be cheaper than option contracts. Hedging risks with forward or future contracts carries the risk of the firm not being able to take advantage of positive movements in the exchange rate. The advantage of options is that the option is exercised only if the exchange rate moves in the right direction. Since fewer and fewer firms would benefit from such movement, it would be wise to hedge risks using forward or future contracts rather than options. 


\section{References}

Acharya, V. V. and S. Steffen (2015). The "greatest" carry trade ever? Understanding eurozone bank risks. Journal of Financial Economics 115(2), 215-236.

Adler, M. and B. Dumas (1984). Exposure to currency risk: definition and measurement. Financial Management, 41-50.

Bartram, S. M. (2007). Corporate cash flow and stock price exposures to foreign exchange rate risk. Journal of Corporate Finance 13(5), 981 - 994.

Bodnar, G. M. and W. M. Gentry (1993). Exchange rate exposure and industry characteristics: evidence from Canada, Japan, and the USA. Journal of International Money and Finance 12(1), 29-45.

Bodnar, G. M. and M. F. Wong (2003). Estimating exchange rate exposures: issues in model structure. Financial Management, 35-67.

Booth, L. and W. Rotenberg (2010). Assessing foreign exchange exposure: Theory and application using canadian firms. Journal of International Financial ManagementEs Accounting 2(1), 1-22.

Brun-Aguerre, R., A. Fuertes, and M. Greenwood-Nimmo (2015). Heads I Win, Tails You Lose: Asymmetry in Aggregate Exchange Rate Pass-Through. Journal of the Royal Statistical Society: Series A., forthcoming.

Buchinsky, M. (1995). Estimating the asymptotic covariance matrix for quantile regression models a Monte Carlo study. Journal of Econometrics 68(2), 303-338.

Cepparulo, A., J. C. Cuestas, and M. Intartaglia (2017). Financial development, institutions, and poverty alleviation: an empirical analysis. Applied Economics 49(36), 3611-3622.

Chkili, W., C. Aloui, and D. K. Nguyen (2012). Asymmetric effects and long memory in dynamic volatility relationships between stock returns and exchange rates. Journal of International Financial Markets, Institutions and Money 22(4), 738757.

Chue, T. K. and D. Cook (2008). Emerging market exchange rate exposure. Journal of Banking \& Finance 32(7), 1349-1362.

Cuestas, J. C. and B. Tang (2015). Asymmetric Exchange Rate Exposure of Stock Returns: Empirical Evidence from Chinese Industries. Working Paper, Department of Economics, University of Sheffield.

Dominguez, K. M. and L. L. Tesar (2001). A reexamination of exchange-rate exposure. The American Economic Review 91(2), 396-399.

Dominguez, K. M. and L. L. Tesar (2006). Exchange rate exposure. Journal of International Economics 68(1), 188-218.

Dornbusch, R. and S. Fischer (1980). Exchange rates and the current account. The American Economic Review 70(5), 960-971. 
Dranev, Y. and M. Babushkin (2014). Asymmetric Exchange-Rate Exposure in BRIC Countries. Working paper at the National Research University Higher School of Economics (HSE)..

Du, D. and $\mathrm{O} . \mathrm{Hu}$ (2012). Exchange rate risk in the US stock market. Journal of International Financial Markets Institutions \&3 Money 22(1), 137-150.

Frankel, J. A. and S.-J. Wei (2007). Assessing China's exchange rate regime. Economic Policy 22(51), 576-627.

Greenwood-Nimmo, M. and Y. Shin (2013). Taxation and the asymmetric adjustment of selected retail energy prices in the UK. Economics Letters 121(3), $411-416$

He, J. and L. K. Ng (1998). The foreign exchange exposure of Japanese multinational corporations. The Journal of Finance 53(2), 733-753.

Hodder, J. E. (1982). Exposure to exchange-rate movements. Journal of International Economics 13(3), 375-386.

Hsu, C.-C., R. Yau, and J.-Y. Wu (2009). Asymmetric exchange rate exposure and industry characteristics: evidence from Japanese data. Hitotsubashi Journal of Economics, 57-69.

Huffman, S. P., S. D. Makar, and S. B. Beyer (2010). A three-factor model investigation of foreign exchange-rate exposure. Global Finance Journal 21(1), 1-12.

Jorion, P. (1990). The exchange-rate exposure of US multinationals. Journal of Business, 331-345.

Khoo, A. (1994). Estimation of foreign exchange exposure: an application to mining companies in Australia. Journal of International Money and Finance 13(3), 342363.

Koenker, R. (2005). Quantile regression. Number 38. Cambridge university press.

Koenker, R. and G. Bassett Jr (1978). Regression quantiles. Econometrica: Journal of the Econometric Society, 33-50.

Koutmos, G. and A. D. Martin (2003). Asymmetric exchange rate exposure: theory and evidence. Journal of International Money and Finance 22(3), 365-383.

Koutmos, G. and A. D. Martin (2007). Modeling time variation and asymmetry in foreign exchange exposure. Journal of Multinational Financial Management 17(1), 61-74.

Li, H., H. Ma, and Y. Xu (2015). How do exchange rate movements affect Chinese exports? A firm-level investigation. Journal of International Economics 97(1), $148-161$.

Martin, A. D. and L. J. Mauer (2003). Exchange rate exposures of US banks: a cash flow-based methodology. Journal of Banking 83 Finance 27(5), 851-865.

Mattoo, A., P. Mishra, and A. Subramanian (2012). Spillover Effects of Exchange Rates: A Study of the Renminbi. Peterson Institute for International Economics Working Paper (12-4). 
Miao, B., S. Zhou, J. Nie, and Z. Zhang (2013). Renminbi exchange rate exposure: evidence from Chinese industries. Journal of Chinese Economic $\&$ Business Studies 11(4), 229-250.

Muller, A. and W. F. Verschoor (2006). Asymmetric foreign exchange risk exposure: Evidence from US multinational firms. Journal of Empirical Finance 13(4), 495518.

Muller, A. and W. F. Verschoor (2007). Asian foreign exchange risk exposure. Journal of the Japanese and International Economies 21(1), 16-37.

Nucci, F. and A. F. Pozzolo (2001). Investment and the exchange rate: An analysis with firm-level panel data. European Economic Review 45(2), 259-283.

Pesaran, M. H., Y. Shin, and R. J. Smith (2001). Bounds testing approaches to the analysis of level relationships. Journal of Applied Econometrics 16 (3), 289-326.

Phylaktis, K. and F. Ravazzolo (2005). Stock prices and exchange rate dynamics. Journal of International Money and Finance 24(7), 1031-1053.

Shin, Y., B. Yu, and M. Greenwood-Nimmo (2014). Modelling asymmetric cointegration and dynamic multipliers in a nonlinear ARDL framework. In Festschrift in Honor of Peter Schmidt, pp. 281-314. Springer.

Tang, B. (2015). Exchange Rate Exposure of Chinese Firms at the Industry and Firm Level. Review of Development Economics 19(3), 592-607.

Williamson, R. (2001). Exchange rate exposure and competition: evidence from the automotive industry. Journal of Financial Economics 59(3), 441-475.

Wong, T.-C., J. Wong, and P. Leung (2009). The foreign exchange exposure of Chinese banks. China Economic Review 20(2), 174-182.

Wooldridge, J. M. (2010). Econometric analysis of cross section and panel data. MIT press.

Zhou, X. (2009). The reform of the international monetary system. Equilibri 13(2), $161-166$. 
Table 1: Summary Statistics

\begin{tabular}{ccccccc}
\hline Var. $(\mathrm{N})$ & Mean & Std.Dev & Min & Max & $\mathrm{JB}_{\text {prob }}(\mathrm{N})$ & Obs. \\
\hline Panel A: Stock returns and exchange rate movements & & \\
Banks (16) & 0.013 & 0.108 & -0.262 & 0.429 & $0.155(4)$ & 121 \\
B shares (15) & 0.021 & 0.177 & -0.363 & 1.219 & 0.000 & 236 \\
Others (172) & 0.020 & 0.176 & -0.369 & 1.223 & $0.023(9)$ & 202 \\
All (203) & 0.020 & 0.171 & -0.360 & 1.160 & $0.032(13)$ & 198 \\
Market returns & 0.012 & 0.109 & -0.237 & 0.958 & 0.000 & 258 \\
RER & 0.001 & 0.008 & -0.026 & 0.035 & 0.004 & 258 \\
TWEER & 0.003 & 0.015 & -0.046 & 0.045 & 0.935 & 258 \\
Panel B: Firm characteristics & & & & \\
Total assets(M ¥) & 316,183 & $1,510,000$ & 211.48 & $11,700,000$ & 0.000 & 203 \\
EPS & 0.227 & 0.258 & -0.101 & 0.451 & 0.000 & 203 \\
OPI2Asset $(\%)$ & 19.026 & 12.512 & 1.297 & 61.423 & 0.000 & 203 \\
INI2Asset $(\%)$ & 1.262 & 3.394 & -0.846 & 45.108 & 0.000 & 203 \\
Cashf2Asset(\%) & 1.596 & 8.735 & -41.076 & 62.278 & 0.000 & 203 \\
Lia2Asset (\%) & 115.049 & 53.892 & 0.626 & 230.778 & 0.109 & 203 \\
\hline
\end{tabular}

Notes: Panel A reports summary statistics for stock returns and exchange rate movements. The descriptive statistics for the first four rows are expressed in average terms. $\mathrm{JB}_{\text {prob }}$ indicates the average probabilities of the Jarque-Bera test for normality. $\mathrm{N}$ denotes the number of firms. RER and TWEER are the real exchange rate of USD/RMB and the trade weighted effective exchange rate, respectively. Panel B gives descriptive statistics of firm characteristics. These variables are calculated as the averages over the period 1990q4-2015q2, but the availability of the first financial statements for some newly listed financial firms varies in our sample, for instance, the youngest firm released its first financial statement in 2006q4. The average total assets are measured in millions of Yuan. EPS means earnings per share. OPI2Asset is the ratio of (main business) operating income to total assets. INI2Asset indicates the ratio of investment incomes to total assets. Cash 2 Asset means the ratio of net cash flows to total assets. Lia2Asset denotes the ratio of total liabilities to total assets. 
Table 2: Measuring Symmetric Exchange Rate Exposure

\begin{tabular}{|c|c|c|c|c|c|c|}
\hline & \multicolumn{2}{|c|}{ Before 03/2009 } & \multicolumn{2}{|c|}{ After $03 / 2009$} & \multicolumn{2}{|c|}{ Whole sample period } \\
\hline & TWEER & RER & TWEER & RER & TWEER & RER \\
\hline \multicolumn{7}{|c|}{ Panel A: Banks $(\mathrm{N}=14,16,16)$} \\
\hline Mean & -0.653 & 1.215 & -1.042 & -0.120 & -0.781 & 0.178 \\
\hline Pos. $(\%)$ & 5 & 11 & 1 & 8 & 2 & 11 \\
\hline Neg. $(\%)$ & 9 & 3 & $15(6.67)$ & 8 & $14(7.14)$ & 5 \\
\hline$R_{\text {Ave. }}^{2}$ & 0.069 & 0.058 & 0.026 & 0.008 & 0.023 & 0.011 \\
\hline$A R C H_{N o}$. & 2 & 1 & 3 & 4 & 4 & 5 \\
\hline \multicolumn{7}{|c|}{ Panel B: $B$ shares $(\mathrm{N}=15,15,15)$} \\
\hline Mean & -0.397 & -1.798 & -1.575 & -0.350 & -0.786 & -1.283 \\
\hline Pos. $(\%)$ & 4 & 0 & $1(100)$ & $6(16.67)$ & 2 & 0 \\
\hline Neg. $(\%)$ & 11 & $15(6.7)$ & $14(14.29)$ & 9 & 13 & $15(6.67)$ \\
\hline$R_{\text {Ave. }}^{2}$ & 0.015 & 0.019 & 0.081 & 0.045 & 0.022 & 0.021 \\
\hline$A R C H_{N o}$ & 3 & 2 & 3 & 5 & 2 & 2 \\
\hline \multicolumn{7}{|c|}{ Panel C: Others $(\mathrm{N}=150,172,172)$} \\
\hline Mean & 0.148 & 0.454 & -1.766 & 0.779 & -0.420 & 0.475 \\
\hline Pos. $(\%)$ & $91(5.49)$ & $96(7.29)$ & 16 & 124 & $54(1.85)$ & $111(7.21)$ \\
\hline Neg. $(\%)$ & 69 & $64(1.56)$ & $156(21.80)$ & $48(4.17)$ & $118(6.78)$ & $61(3.28)$ \\
\hline$R_{\text {Ave. }}^{2}$ & 0.022 & 0.025 & 0.046 & 0.021 & 0.017 & 0.015 \\
\hline$A R C H_{N o}$ & 46 & 45 & 26 & 31 & 50 & 51 \\
\hline \multicolumn{7}{|c|}{ Panel D: Whole sample financial firms $(\mathrm{N}=189,203,203)$} \\
\hline Mean & 0.046 & 0.332 & -1.695 & 0.625 & -0.476 & 0.322 \\
\hline Pos. $(\%)$ & $100(5)$ & $107(6.54)$ & $18(5.56)$ & $138(7.25)$ & $58(1.72)$ & $122(6.56)$ \\
\hline Neg. $(\%)$ & 89 & $82(2.43)$ & $185(20)$ & $65(3.08)$ & $145(6.90)$ & $81(3.70)$ \\
\hline$R_{\text {Ave. }}^{2}$ & 0.026 & 0.027 & 0.047 & 0.021 & 0.018 & 0.015 \\
\hline$A R C H_{N o}$. & 51 & 48 & 32 & 40 & 56 & 58 \\
\hline
\end{tabular}

Notes: This table reports summaries of the symmetric exchange rate exposure estimates according to equation (1), and equation (2) if $\mathrm{ARCH}$ effects exist. TWEER and RER designate the trade weighted effective exchange rate and real exchange rate of USD/RMB, respectively. $\mathrm{N}$ means the number of firms estimated in each time period. Pos. (\%) and Neg.(\%) indicate the numbers of positive and negative exchange rate exposures, respectively, and \% in parentheses represent the percentage of significant positive or negative exchange rate exposures. $R_{\text {Ave. }}^{2}$ designates the average $\mathrm{R}$-square from symmetric exchange rate exposure estimates by firm. $A R C H_{N o}$. means the number of symmetric exchange rate exposure estimates that exhibits ARCH effects. 
Table 3: Measuring Asymmetric Exchange Rate Exposure

\begin{tabular}{|c|c|c|c|c|c|c|}
\hline & \multicolumn{2}{|c|}{ Before 03/2009 } & \multicolumn{2}{|c|}{ After $03 / 2009$} & \multicolumn{2}{|c|}{ Whole sample period } \\
\hline & TWEER & RER & TWEER & RER & TWEER & RER \\
\hline \multicolumn{7}{|c|}{ Panel A: Banks $(\mathrm{N}=5,16,16)$} \\
\hline$\beta^{+}$ & 3.618 & -2.681 & 0.162 & 1.287 & 0.842 & 0.628 \\
\hline$\beta^{-}$ & 2.968 & -4.059 & -1.076 & -0.219 & 0.433 & 0.104 \\
\hline$\beta^{+}-\beta^{-}$ & 1 & 3 & 5 & 3 & 6 & 4 \\
\hline PSS & 0 & 1 & 0 & 0 & 4 & 2 \\
\hline$L M(2)$ & 3 & 5 & 14 & 12 & 15 & 15 \\
\hline$A R C H$ & 5 & 5 & 14 & 14 & 14 & 15 \\
\hline $\bar{R}^{2}$ & 0.396 & 0.464 & 0.468 & 0.463 & 0.493 & 0.506 \\
\hline \multicolumn{7}{|c|}{ Panel B: $B$ shares $(\mathrm{N}=15,15,15)$} \\
\hline$\beta^{+}$ & 4.387 & -3.123 & -0.767 & -0.245 & 2.237 & -1.289 \\
\hline$\beta^{-}$ & 4.274 & -3.370 & -1.465 & -1.307 & 2.151 & -1.532 \\
\hline$\beta^{+}-\beta^{-}$ & 0 & 0 & 3 & 8 & 0 & 0 \\
\hline PSS & 1 & 0 & 2 & 7 & 7 & 3 \\
\hline$L M(2)$ & 14 & 11 & 14 & 14 & 13 & 12 \\
\hline$A R C H$ & 13 & 12 & 13 & 12 & 13 & 11 \\
\hline $\bar{R}^{2}$ & 0.284 & 0.480 & 0.433 & 0.471 & 0.470 & 0.467 \\
\hline \multicolumn{7}{|c|}{ Panel C: Others $(\mathrm{N}=148,172,172)$} \\
\hline$\beta^{+}$ & 3.418 & -0.643 & -0.600 & 2.732 & 2.034 & 0.026 \\
\hline$\beta^{-}$ & 3.363 & -1.274 & -1.666 & 0.515 & 1.728 & -0.871 \\
\hline$\beta^{+}-\beta^{-}$ & 35 & 44 & 25 & 73 & 29 & 69 \\
\hline PSS & 75 & 56 & 11 & 34 & 92 & 89 \\
\hline$L M(2)$ & 123 & 100 & 147 & 143 & 147 & 127 \\
\hline$A R C H$ & 123 & 118 & 153 & 160 & 147 & 134 \\
\hline $\bar{R}^{2}$ & 0.514 & 0.541 & 0.499 & 0.510 & 0.507 & 0.513 \\
\hline \multicolumn{7}{|c|}{ Panel D: Whole sample financial firms $(\mathrm{N}=168,203,203)$} \\
\hline$\beta^{+}$ & 3.511 & -0.925 & -0.552 & 2.398 & 1.955 & -0.024 \\
\hline$\beta^{-}$ & 3.433 & -1.544 & -1.605 & 0.322 & 1.657 & -0.843 \\
\hline$\beta^{+}-\beta^{-}$ & 36 & 47 & 33 & 84 & 35 & 73 \\
\hline PSS & 76 & 57 & 13 & 41 & 103 & 94 \\
\hline $\operatorname{LM}(2)$ & 140 & 116 & 175 & 169 & 175 & 154 \\
\hline$A R C H$ & 141 & 135 & 180 & 186 & 174 & 159 \\
\hline $\bar{R}^{2}$ & 0.506 & 0.533 & 0.492 & 0.503 & 0.503 & 0.509 \\
\hline
\end{tabular}

Notes: This table reports summaries of the asymmetric exchange rate exposure estimates for each sample period according to equation (4). TWEER and RER designate the trade weighted effective exchange rate and real exchange rate of USD/RMB, respectively. $\mathrm{N}$ means the number of firms estimated in each time period. $\beta^{+}$and $\beta^{-}$ are the average exposure coefficients for positive and negative exchange rate shocks, respectively. $\beta^{+}-\beta^{-}$reports the number of estimates that the null $\beta^{+}-\beta^{-}=0$ is rejected in the asymmetry test. PSS denotes the Pesaran et al. (2001) $F$-test of the null hypothesis $\rho=\beta^{+}=\beta^{-}=\lambda^{+}=\lambda^{-}=0$ against the alternative of joint significance. The critical value for the PSS $F$-test is 4.14 at the $10 \%$ level. PSS reports the number of $F$ statistics that reject the null hypothesis at the $10 \%$ level. $L M(2)$ denotes the number of NARDL estimates that accept the null hypothesis (no serial correlation) in the Breusch-Godfrey test. ARCH indicates the number of NARDL estimates that do not have ARCH effects. $\bar{R}^{2}$ denotes the average value of the adjusted $R^{2}$. 


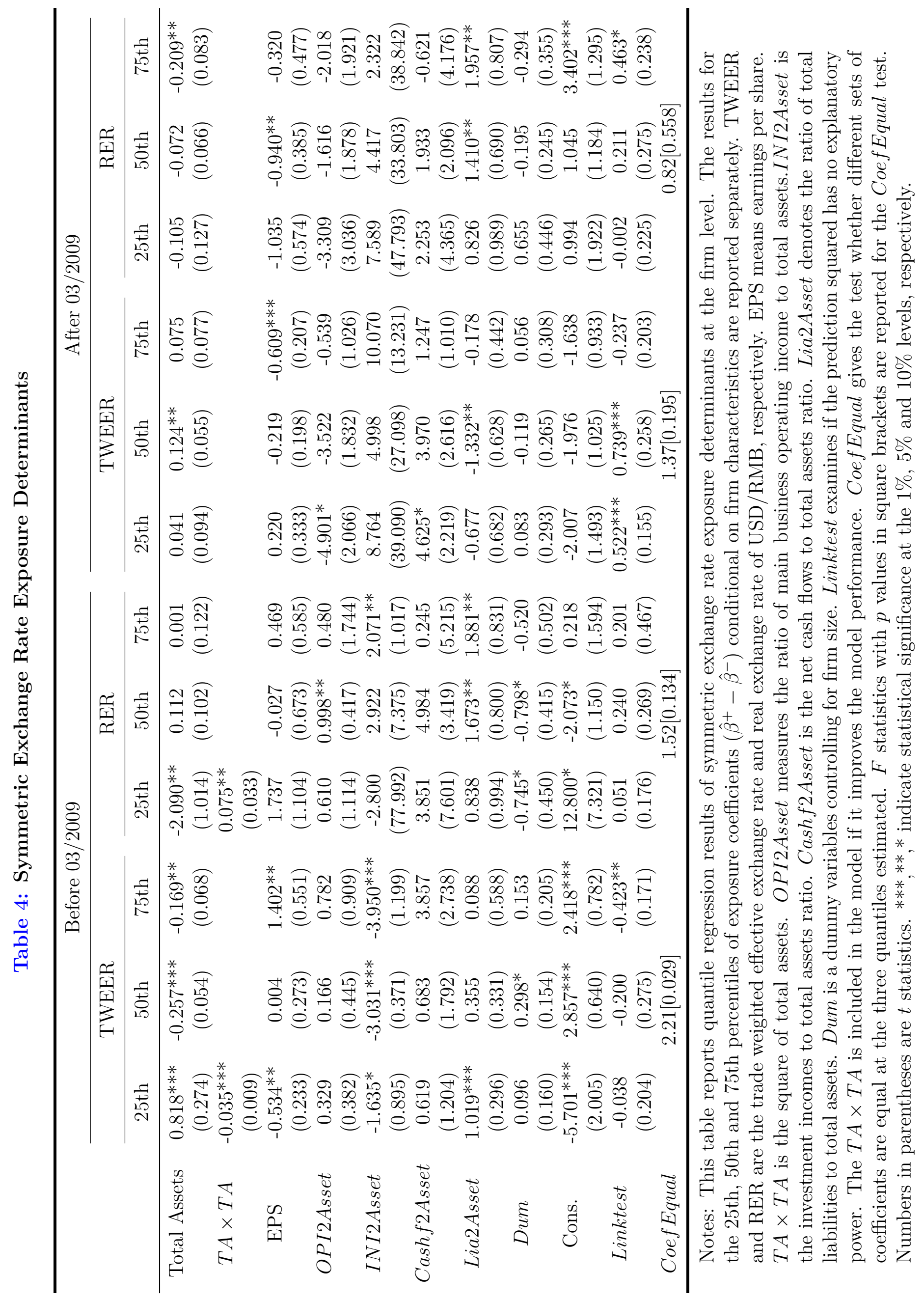




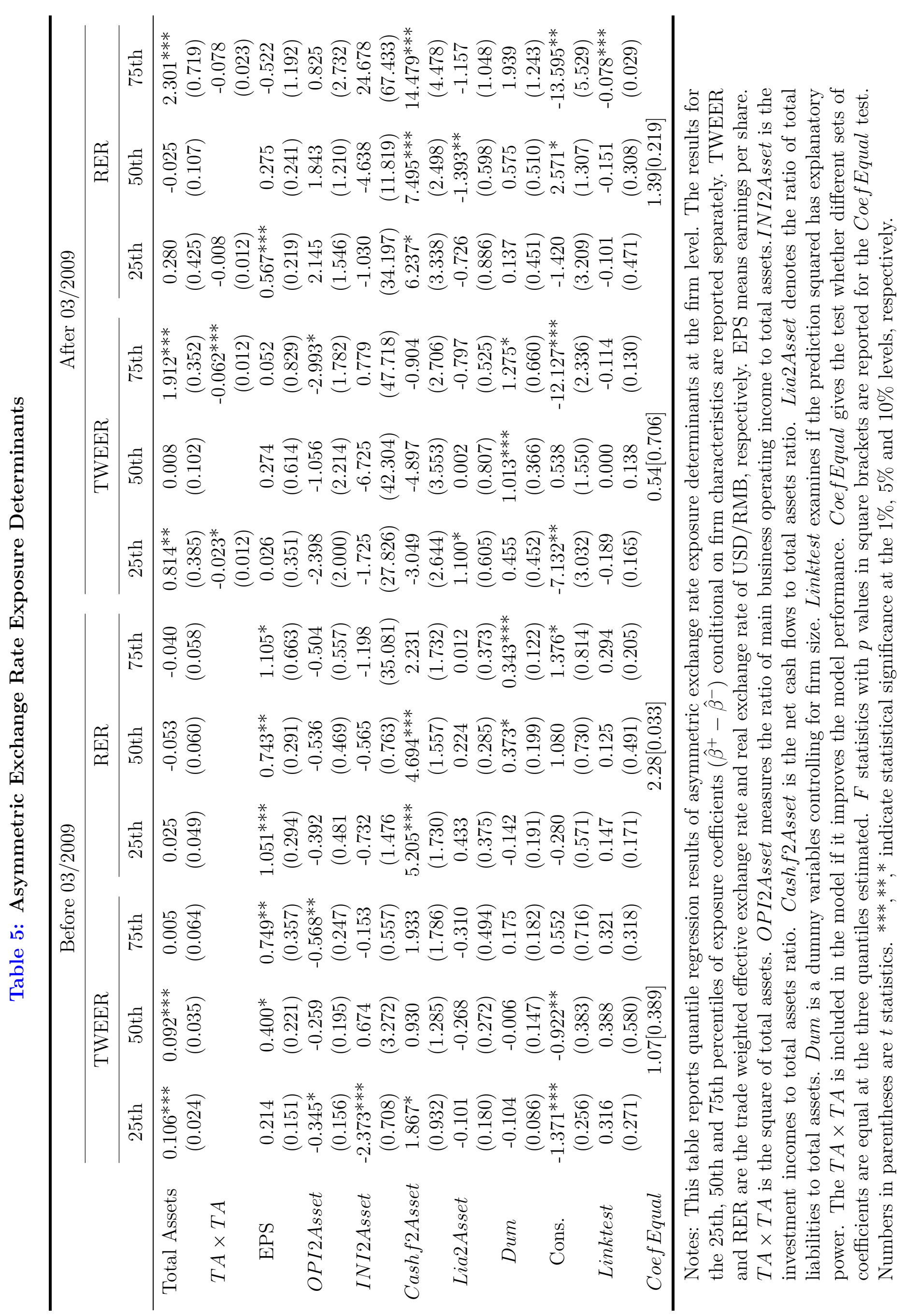

